\title{
A Decade of Data Discloses the Window Is Still Not Clear
}

In this issue of The Journal, Keystone, et al publish a 10-year prospective trial: a remarkable feat given the myriad difficulties of completing clinical trials these days ${ }^{1}$. It is the longterm extension (LTE) of the PREMIER trial, and a fairly large number of patients $(250$, or about $30 \%)$ complete the 10-year followup. The authors clearly concede the limitations of all LTE trials, most importantly that they are essentially completers' analyses. Very little can be learned from those patients not completing the trial, and any and all conclusions must be interpreted in the context that they are only about those patients who presumably did well and therefore continued in the study. This article does successfully address these inherent issues.

The PREMIER trial was more interesting than some of the similar trials conducted at about the same time because the double-blinded portion was longer than most at 2 years, and there were 3 arms; methotrexate (MTX), adalimumab (ADA), and the combination of the $2(\mathrm{MTX}+\mathrm{ADA})^{2}$. The patients in the study have early, MTX-naive, and very aggressive disease, many with multiple erosions at baseline. This may be a different population than that seen in some very recent trials, and may not be typical of any rheumatologist's rheumatoid arthritis (RA) practice today, and the authors acknowledge this possibility. Early disease in this article is defined as less than 3 years of disease without details as to whether this is from onset of symptoms, joint swelling, or time of diagnosis.

The simplest conclusions from the trial are the same as those demonstrated by other LTE trials, namely that the treatment arms with ADA demonstrate sustained efficacy and that no new safety signals emerged ${ }^{3,4,5}$. The efficacy appears to persist in many patients, despite significant patient dropouts and presumed nonresponders, presented as a sensitivity analysis with nonresponder imputation demonstrating that the percentage of patients who benefit from ADA declines slightly over time. The discussion of treatment-related adverse event rates is tempered by the very long duration of the LTE, and the significant number of withdrawals from the study. The lymphoma risk was slightly higher than that reported in other studies, and this obser-

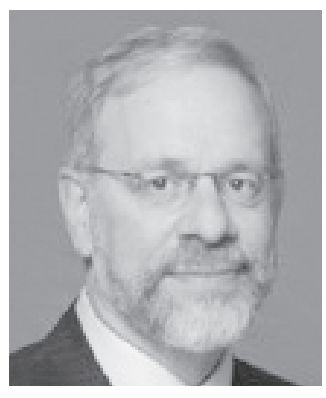

vation may warrant close followup in all longterm patient cohorts exposed to ADA and other tumor necrosis factor (TNF) inhibitors to see if it is truly increased and therefore important.

Given all the limitations and inconsistencies of many LTE trials (many of which have been summarized elsewhere ${ }^{5,6,7}$ ), given the limitations of this specific study (many of which are conceded by the authors), and given that MTX use during this LTE was allowed at the discretion of the investigators and may have been due to inadequate response or other sentiments, the authors are still able to conclude that the window of opportunity for initiating successful combination therapy was demonstrated in the disease control achieved by this group in the first 2 years of therapy and maintained for up to 10 years compared to the other 2 monotherapy groups. Those patients treated initially with the combination of the TNF inhibitor and MTX achieved better disease control, and the other 2 monotherapy groups never seemed to match that level of control, despite the addition of ADA or MTX after Year 2. This conclusion is probably strengthened by the observation that only $18 \%$ of patients discontinued the study for lack of efficacy.

The window of opportunity is supposed to represent an early phase of RA during which treatment is at least more, if not most, successful, presumably because the underlying immunopathologic processes are not yet fixed or immutable $8,9,10,11$. This is the interval during which the disease is theoretically most susceptible to disease-modifying medications. The related hypothesis is that treatment during this period may alter RA progression, perhaps changing the natural history of the disease. The implications of such a therapeutic window are enormous, and include not only the design of more effective treatment protocols but also the potential for substantial cost savings, because the need for longterm expensive treatments might be substantially reduced.

Whether such a window exists has been discussed for years, starting around a decade ago, at the time PREMIER was initiated ${ }^{2,8,9}$. There is uncertainty about whether it represents a formative stage of RA, perhaps before the

See 10-year adalimumab results, page 5

Personal non-commercial use only. The Journal of Rheumatology Copyright @ 2014 . All rights reserved. 
disease is truly self-perpetuating, or whether it only directly reflects the timely effects of early, aggressive treatment. The former might be defined immunologically, while the latter might have more and different variables. If it is a window, why and when it opens and closes remain unknown.

Evidence supporting this window of opportunity for RA treatment has recently been reviewed, and the conclusion supported the notion of such an opportunity ${ }^{11}$. The timing and duration of this phase were not clearly defined. The first 12 weeks after the onset of symptoms has previously been suggested as a possible time frame, although the definition of symptom onset has been highly variable in many previous studies. The time frame may indeed be longer, as others have suggested ${ }^{11}$. This has led to a proposal for clearer definitions of disease duration in clinical trials, and this published viewpoint presents a clear summary of many of the issues involved in the timing of such a window ${ }^{12}$. Data on duration of disease since the onset of symptoms and joint swelling as well as duration of disease based on fulfillment of classification criteria are suggested as most useful.

In the metaanalysis reviewing the literature support for the window of opportunity, prolonged RA symptom duration was associated with radiographic progression and a reduced likelihood of disease-modifying antirheumatic drug (DMARD)-free sustained remission. These authors also addressed the limitations of their study, including publication and citation bias, different adjustment factors in the included studies, and issues regarding their inclusion and exclusion criteria for the included articles. Nonetheless, their systematic literature review, which included studies mostly using conventional DMARD, was able to endorse the window of opportunity concept. Interestingly, the current article by Keystone, et al would not have qualified for the literature review because the 3-year early disease definition would not have met one of the inclusion criteria.

This study nevertheless validates the superiority of ADA + MTX over monotherapy in clinical disease control and the inhibition of radiographic damage during the 2-year double-blind phase. Even after scrutinizing the data with skepticism, the apparent advantages achieved within the first 2 years of the study did seem to be maintained over the 8-year open-label extension. Despite every caveat about the limitations of this and other LTE trials, both phases of this study may be interpreted as demonstrating the window of opportunity for treating their specific study cohort with initial combination therapy as soon as possible.

Various epidemiological registries provide important data regarding efficacy and safety of RA therapies over long observation periods, but such data also have inherent limitations since they are retrospective and dependent on selected contributors for documentation. Longterm prospective trials also provide valuable data, also with described limitations. The article by Keystone, et al is better than most, concise and not overreaching, and is a significant contribution to the calculus supporting the concept of a window of opportunity for the early, intensive treatment of certain patients with RA, particularly those with aggressive disease. The precise dimensions of the window have yet to be determined, but the window appears small. It is also still unclear.

\author{
MARC COHEN, MD, \\ Division of Rheumatology, \\ University of Colorado Medical Center, \\ 668 Humboldt St., \\ Denver, Colorado 80218, USA.
}

Address correspondence to Dr. Cohen; E-mail: mcohen@rheumdoc.net

\section{REFERENCES}

1. Keystone E, Breedveld F, van der Heijde D, Landewe R, Florentinus S, Arulmani U, et al. Longterm effect of delaying combination therapy with tumor necrosis factor inhibitor in patients with aggressive early rheumatoid arthritis: 10-year efficacy and safety of adalimumab from the randomized controlled PREMIER trial with open-label extension. J Rheumatol 2014;41:5-14.

2. Breedveld FC, Weisman MH, Kavanaugh AF, Cohen SB, Pavelka $\mathrm{K}$, van Vollenhoven $\mathrm{R}$, et al. The PREMIER study: multicenter, randomized, double-blind clinical trial of combination therapy with adalimumab plus methotrexate versus methotrexate alone or adalimumab alone in patients with early, aggressive rheumatoid arthritis who had not had previous methotrexate treatment. Arthritis Rheum 2006;54:26-37.

3. Burmester GR, Panaccione R, Gordon KB, McIlraith MJ, Lacerda AP. Adalimumab: long-term safety in 23,458 patients from global clinical trials in rheumatoid arthritis, juvenile idiopathic arthritis, ankylosing spondylitis, psoriatic arthritis, psoriasis and Crohn's disease. Ann Rheum Dis 2013;72:517-24.

4. Weinblatt ME, Bathon JM, Kremer JM, Fleischmann RM. Schiff MH, Martin RW, et al. Safety and efficacy of etanercept beyond 10 years of therapy in North American patients with early and longstanding rheumatoid arthritis. Arthritis Care Res 2011; 63:373-82.

5. Buch MH, Aletaha D, Emery P, Smolen JS. Reporting of long-term extension studies: lack of consistency calls for consensus. Ann Rheum Dis 2011;70:886-90.

6. Fleischmann RM, Kavanaugh AF, Smolen JS. Methodological aspects and the interpretation of clinical trials: lessons from the TEAR trial. Rheumatology 2013;52:409-10.

7. Taylor WJ, Weatherall M. What are open-label extensions for? J Rheumatol 2006;33:642-3.

8. O'Dell JR. Treating rheumatoid arthritis early: a window of opportunity? Arthritis Rheum 2002;46:283-5.

9. Boers M. Understanding the window of opportunity concept in early rheumatoid arthritis. Arthritis Rheum 2003;48:1771-4.

10. Raza K. The Michael Mason prize: Early rheumatoid arthritis the window narrows. Rheumatology 2010;49:406-10.

11. van Nies JA, Krabben A, Schoones JW, Huizinga TW, Kloppenburg M, van der Helm-van Mil AH. What is the evidence for the presence of a therapeutic window of opportunity in rheumatoid arthritis? A systematic literature review. Ann Rheum Dis 2013; April 9 (E-pub ahead of print).

12. Raza K, Saber TP, Kvien TK, Tak PP, Gerlag DM. Timing the therapeutic window of opportunity in early rheumatoid arthritis: proposal for definitions of disease duration in clinical trials. Ann Rheum Dis 2012;71:1921-3.

J Rheumatol 2014;41:1-2; doi:10.3899/jrheum.131116 